\title{
Analytical investigation of non-Fickian receptor-mediated endocytosis
}

\author{
Milad Rismanian ${ }^{1}$, Behzad Damirchi $^{2 *}$ \\ ${ }^{1}$ Department of Mechanical Engineering, Sharif University of Technology, Tehran, Iran \\ ${ }^{2}$ Department of Mechanical Engineering, Pennsylvania State University, University Park, PA, 16802, United States \\ * To whom correspondence should be addressed: behzad.damirchi@psu.edu
}

\begin{abstract}
The most important process in which viruses and bioparticles can enter the animal cell is receptor mediated endocytosis. The main propellant of this phenomenon is the attraction between receptor molecules floating in the lipid bilayer membrane of the host cell and ligand molecules on the target. In this paper, the aforementioned phenomenon is investigated analytically assuming that the diffusion model of the receptor molecules in the lipid bilayer is non-Fickian. Penetration time of the target molecule in the host cell shows that there is a critical limit for the target molecule size. The molecules larger than this critical size will experience an oscillatory motion without passing the host cell membrane. For instance, it is found that the maximum diameter for a typical target molecule with dimensionless relaxation time of 5 for receptor diffusion into a cell membrane is 0.22 of the membrane length.
\end{abstract}

Keywords: Endocytosis, Host cell, Penetration, Non-Fickian diffusion, Analytical solution

\section{Introduction}

There are different mechanisms regarding penetration of a molecule into a host cell. Ion transition through cell membrane is usually performed aided by protein channels placed in the membrane. This process can be done selectively or non-selectively [1-3]. Large molecules use larger protein channels to be able to penetrate into their host cell which the most familiar one is water channel $[4,5]$. Cell penetrating peptides permeate into cell membrane via water pore formation on the membrane [6]. Some of the larger molecules will penetrate via endocytosis process in which the attraction between target molecule ligands and membrane receptors causes the molecule to be surrounded by cell membrane [7] and get absorbed by the cell. Molecular dynamics simulations can reveal detailed observations at this scale. The application of this technique on studies such as assembly of high density proteins (HDL) [7-8], penetration of peptides into living cell [6] and homo-oligomerization of integrin proteins on the membrane [9] have showed the ability of this method to model and further understanding of nano-scale biological processes. 
Receptor-mediated endocytosis is the most important mechanism for virus penetration into a cell. After penetration of viruses, they will affect the cell and exit via a similar mechanism named exocytosis. Echavarria-Heras et al. [11] proposed a theoretical model to investigate the effect of mechanisms that influence surface aggregation patterns of LDL receptors near coated pits. Size effect of target molecule in endocytosis is the subject of many researches [12-19]. Prabha et al. [11] examined endocytosis of PLGA nanoparticles through cell membrane experimentally and found that smaller nanoparticles $(70 \mathrm{~nm})$ have higher transfection than the larger ones $(200 \mathrm{~nm})$ in different cell lines. Osaki et al. [11] suggested the optimal size of approximately $50 \mathrm{~nm}$ for cellular uptake. Gao et al. [20] and shi et al. [21] proposed some models for concentration distribution in the endocytosis process. They considered Fick's law for receptor diffusion in a membrane and solved it for infinite membrane length analytically and for finite length numerically. They suggested that the results of finite length model are closer to real phenomenon. Rismanian et al. [22] showed that Fick's law cannot predict the diffusion phenomenon in the cell length and time scales. They proposed a lagged model in which there is a phase lag between mass flux and its producing agent i.e. concentration gradient for mass transport in the cell scale for biological phenomena.

In this study receptor-mediated endocytosis of a target molecule into a host cell is investigated analytically. A non-Fickian lagged model and the finite length for the cell membrane are considered. The results showed that molecules larger than a certain size cannot penetrate to the cell. The value of this threshold $-\mathrm{A}_{\mathrm{cr}}$-is related to the lag time of receptor diffusion into membrane cell. This finding can help pharmacologists to choose optimum size of drugs to penetrate into a definite cell and not penetrate to others.

\section{Mathematical modeling}

Fig.1(a) shows the change of the receptor molecules concentration on the host cell membrane due to descending of the target cells. Before contact with the target molecules, the receptors are assumed to be distributed uniformly on the cell membrane in the state of maximum entropy with constant concentration of $\xi_{0}$. After contacting, the receptor concentration increases to the level of ligand concentration $\xi_{L}$. So, the concentration along cell membrane can be divided into two parts; the first part, $0<s<a(t)$, where the concentration assumed to be $\xi_{L}$ and the second part, $a(t)<s<L$, where the concentration changes along the host membrane length. The a(t) is half of the contacting area of ligand-receptor which is increasing with time from 0 to half of the target molecule circumference and $\mathrm{L}$ is half of the host membrane length. The receptors in the vicinity of the contact region are drawn by diffusion, resulting in a local decrease in receptor concentration in that region.

The diffusive process of receptors toward the binding site can be characterized by anon-uniform receptor distribution function $\xi(s, t)$ (Fig.1(b)). The more time passes, the size of the contact area $2 \mathrm{a}(\mathrm{t})$ increases. 


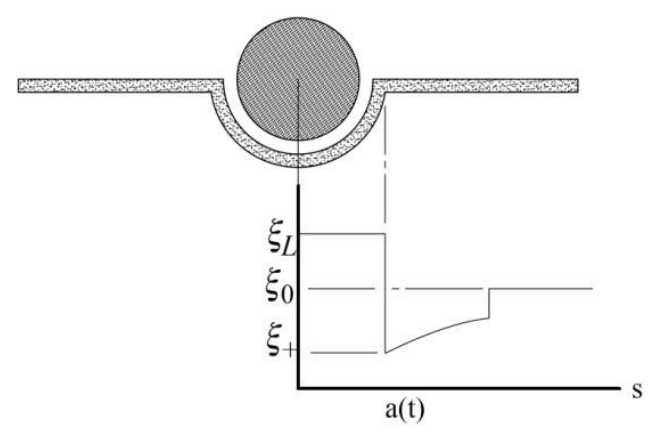

Fig.1(a) The penetration of the target in the host cells (the Endocytosis phenomenon), (b) The concentration of the receptor molecules along the host cell membrane

Considering the continuity and non-Fickian mass transport equations (Eq. (1), (2)), the governing equation of the receptor molecules diffusion in the second part of $2 \mathrm{D}$ configuration of the cell membrane can be obtained as Eq. (3).

$$
\begin{aligned}
& \frac{\partial \xi(s, t)}{\partial t}=-\frac{\partial J(s, t)}{\partial s} \\
& J(s, t)+\tau \frac{\partial J(s, t)}{\partial t}=-D \frac{\partial \xi(s, t)}{\partial s} \\
& \frac{\partial \xi(s, t)}{\partial t}+\tau \frac{\partial^{2} \xi(s, t)}{\partial t^{2}}=D \frac{\partial^{2} \xi(s, t)}{\partial s^{2}} \quad(a(t)<s<L)
\end{aligned}
$$

where $J, \tau$, D represent the mass flux of receptor, the relaxation lag time and receptor diffusion coefficient through the membrane, respectively. The relaxation lag time in non-Fickian mass transport equation is related to the speed of mass transport $v=\sqrt{\frac{D}{\tau}}$.

The boundary and initial conditions for Eq. (3) are assumed through Eqs. (4-7):

$$
\begin{aligned}
& \xi(a(t), t)=\xi_{+} \\
& \frac{\partial \xi(L, t)}{\partial s}=0 \\
& \xi(s, 0)=\xi_{0} \\
& \frac{\partial \xi(s, 0)}{\partial t}=0
\end{aligned}
$$

where $\xi_{+}$denotes concentration directly in front of the contact edge.

\section{Analytical Solution}


We consider dimensionless variables as follows.

$$
\begin{aligned}
& \theta=\frac{\xi-\xi_{+}}{\xi_{+}-\xi_{0}} \\
& \bar{x}=\frac{s-a}{L-a} \\
& \bar{t}=\frac{D t}{(L-a)^{2}} \\
& \beta=\frac{D \tau}{(L-a)^{2}}
\end{aligned}
$$

The non-dimensional form of the governing equation and its initial and boundary conditions are:

$$
\begin{aligned}
& \frac{\partial \theta}{\partial \bar{t}}+\beta \frac{\partial^{2} \theta}{\partial \bar{t}^{2}}=\frac{\partial^{2} \theta}{\partial \bar{x}^{2}} \quad(0<\bar{x}<1) \\
& \theta(0, \bar{t})=0 \\
& \frac{\partial \theta(1, \bar{t})}{\partial \bar{x}}=0 \\
& \theta(\bar{x}, 0)=-1 \\
& \frac{\partial \theta(\bar{x}, 0)}{\partial \bar{t}}=0
\end{aligned}
$$

The dimensionless concentration of receptor molecules along the host cell membrane can be obtained with the method of separation of variables as Eq. (17).

$$
\theta(\bar{x}, \bar{t})=\sum_{n=0}^{\infty} \sin \left(\lambda_{n} \bar{x}\right)\left[A_{n} \sin (m \bar{t})+B_{n} \cos (m \bar{t})\right] e^{-\frac{\bar{t}}{2 \beta}}
$$

Where corresponding eigen-values are $\lambda_{n}=\left(n+\frac{1}{2}\right) \pi$ and other variables can be expressed by Eqs.

$$
\begin{aligned}
& m=\sqrt{\frac{\lambda_{n}{ }^{2}}{\beta}-\frac{1}{4 \beta^{2}}} \\
& A_{n}=\frac{-1}{2 \beta m} \frac{1}{\lambda_{n}} \\
& B_{n}=\frac{-1}{\lambda_{n}}
\end{aligned}
$$

In order to investigate the problem, the two parameters of $a(t)$ and $\zeta_{+}$are desired to be found.

These parameters can be obtained using two models as below. 


\section{Equation of Membrane thermal fluctuations:}

In order to find $\zeta_{+}$, thermal fluctuations of the membrane should be investigated. Freund and Lin [23] considered the free energy equation for a curved cell membrane in contact with a substrate as Eq. (21).

$$
F(t)=k_{B} T\left[\int_{0}^{a(t)}\left(-\xi_{L} e_{R L}+\xi_{L} \ln \frac{\xi_{L}}{\xi_{0}}+\frac{1}{2} B \kappa_{P}^{2}\right) d s+\int_{a(t)}^{L} \xi \ln \frac{\xi}{\xi_{0}} d s\right]
$$

Where $\mathrm{k}_{\mathrm{B}}$ is the Boltzmann constant, $\mathrm{T}$ is the absolute system temperatureis the energy $k_{B} T e_{R L}$, of a single receptor-ligand bond, $k_{B} T \ln \frac{\xi_{L}}{\xi_{0}}$ and $k_{B} T \ln \frac{\xi}{\xi_{0}}$ are the entropy loss of bound receptors relative to free ones, respectively [24]. $\frac{B k_{B} T \kappa_{P}{ }^{2}}{2}$ is the elastic bending energy of the membrane wrapping around a cylinder with radius of curvature $\kappa_{P}=\frac{1}{a(t)}$ [25]. Thus, the free energy function consists of the energy of receptor-ligand binding, the entropy loss of receptors, and the elastic energy of the cell membrane.

The time derivative of the free energy Eq. (21) is:

$$
\frac{d}{d t} \frac{F(t)}{k_{B} T}=\left(-\xi_{L} e_{R L}+\xi_{L} \ln \frac{\xi_{L}}{\xi_{+}}+\frac{1}{2} B \kappa_{P}^{2}-\xi_{L}+\xi_{+}\right) \frac{d}{d t} a(t)-\int_{a(t)}^{\infty} D \xi\left(\frac{\partial \mu}{\partial s}\right)^{2} d s
$$

where $\mu$ is the chemical potential of a receptor defining as bellow,

$$
\mu(s, t)=1+\ln \left(\frac{\xi}{\xi_{0}}\right)
$$

In order to establish a balance between the rate of free energy reduction by wrapping and the rate of energy dissipation by receptor transport [20], the first term on the right hand side of Eq. (22) must be equal to zero so that

$$
\xi_{L} e_{R L}-\xi_{L} \ln \frac{\xi_{L}}{\xi_{+}}-\frac{1}{2} B \kappa_{P}^{2}+\xi_{L}-\xi_{+}=0
$$




\section{Conservation of receptor quantity}

The total number of receptor on cell membrane is constant during the time. So, a conservation equation can be obtained as Eq. (25)

$\frac{d}{d t} \int_{0}^{a(t)} \xi_{L} d s+\frac{d}{d t} \int_{a(t)}^{L} \xi(s, t) d s=0$

Using the Leibniz rule and Eq. (2), the above equation can be expressed as Eq. (26)

$\left(\xi_{L}-\xi_{+}\right) \frac{d}{d t} a(t)+J(a(t), t)=0$

According to Eq. (3), the mass flux of receptor in $\mathrm{a}(\mathrm{t})$ is

$$
J_{+}(\bar{t})=\sum_{n=0}^{\infty}\left[\left(E_{n} \sin (m \bar{t})+F_{n} \cos (m \bar{t})\right) e^{-\frac{\bar{t}}{2 \beta}}-\bar{B} e^{-\overline{\bar{t}}}\right]
$$

Where:

$$
\begin{aligned}
& C_{n}=-\frac{D \lambda_{n}\left(\xi_{+}-\xi_{0}\right)}{(L-a) \tau} A_{n} \\
& D_{n}=-\frac{D \lambda_{n}\left(\xi_{+}-\xi_{0}\right)}{(L-a) \tau} B_{n} \\
& F_{n}=\frac{\left(-D_{n} \frac{\tau}{2}-C_{n} m \tau^{2}\right)}{\left(\frac{1}{4}+m^{2} \tau^{2}\right)-(\tau+m \tau)} \\
& E_{n}=\frac{D_{n}}{m}-\frac{F_{n}}{2 m \tau}
\end{aligned}
$$

By substituting $\xi_{+}$from Eq. (26) to Eq. (24) we get following relation for rate of a(t) change. Considering initial value of $a(0)=0$ Eq. (32) can be solved.

$$
e_{R L}+\ln \left(1-\frac{J_{+}(\bar{t})}{\xi_{L} \dot{a}(\bar{t})}\right)-\frac{B}{2 \xi_{L} a^{2}(\bar{t})}+\frac{J_{+}(\bar{t})}{\xi_{L} \dot{a}(\bar{t})}=0
$$

\section{Results and discussion}

The results are investigated for concentration distribution and the penetration velocity for a target molecule with the radius of a. It is expected to have more accurate results rather than available 
models, because of including finite length of membrane in our analysis. The penetration time is defined by the time in which $a\left(t_{p}\right)=\pi R$. The values for $B / k_{B} T$ and $e_{R L} / k_{B} T$ are set to 20 and 15 similar to other models $[4,20,25]$. The values of diffusion coefficient, receptor concentration in contact with target molecule and initial concentration of receptors are assumed to be $D=1 \times 10^{-14}\left[\mathrm{~m}^{2} / \mathrm{s}\right]$ [26], $\xi_{L}=5 \times 10^{3}\left[\# / \mu \mathrm{m}^{2}\right]$ and $\xi_{0}=5 \times 10^{1}\left[\# / \mu \mathrm{m}^{2}\right]$ [27-29], respectively. The behavior of the target molecule for different relaxation lag time is investigated to show the effect of lag time on the speed of mass transport.

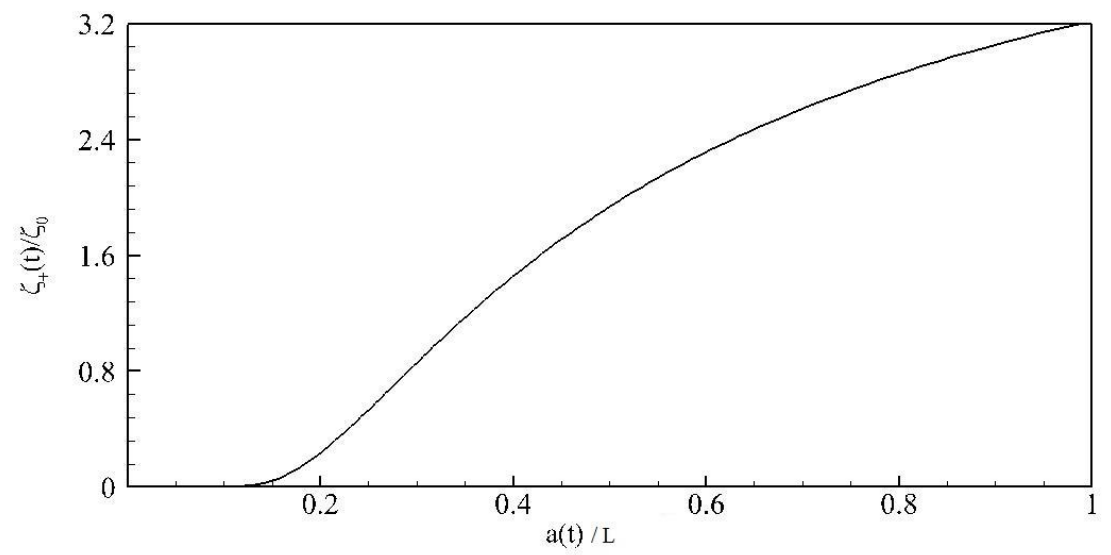

Fig.2. Profile of dimensionless concentration for receptor contacting target molecule directly in front of the contact edge

Fig. 2, shows the profile of dimensionless receptor concentration directly in front of the contact edge as a function of contacting length. As shown, the more contact between target molecule and host cell, the more receptor concentration directly in front of the contact edge. Once the contact starts, the values of contact length and consequently receptor concentration in front of the contact edge are equal to zero. Absence of receptors in start of contact causes the diffusion motion of receptors to this region.

The profile of dimensionless receptor concentration after contact region is shown in Fig. 3 and Fig. 4 for different non-dimensional times. The difference between these two figures is relaxation time which is selected 5 in Fig. 3 and 0.05 in Fig. 4. Fig. 3a and Fig. 3b predict the place of mass shock in dimensionless time of 2 and 3 according to $\bar{x}=\frac{\bar{t}}{\sqrt{\beta}}$ which is in agreement with lag model of mass transport. For $\overline{t_{*}}=\sqrt{\beta}$, the mass shock reaches to the end of the membrane length and reflected back. After that time, Fig. 3c, the amplitude of the mass shock will decrease. Then after repeated backward and forward motions the shock will be damped. 
Comparison between Fig. 3 and Fig. 4 shows that in smaller relaxation times, the receptor diffusion behavior obtained from lag model is close to Fick's model. According to Fig. 4, in small relaxation time for receptors one can use Fick's model instead of lag model in normal time scales. In contrast, when dealing with phenomena in which time scales are small, using Fick's model could cause considerable error in predicting actual behavior of the phenomena.

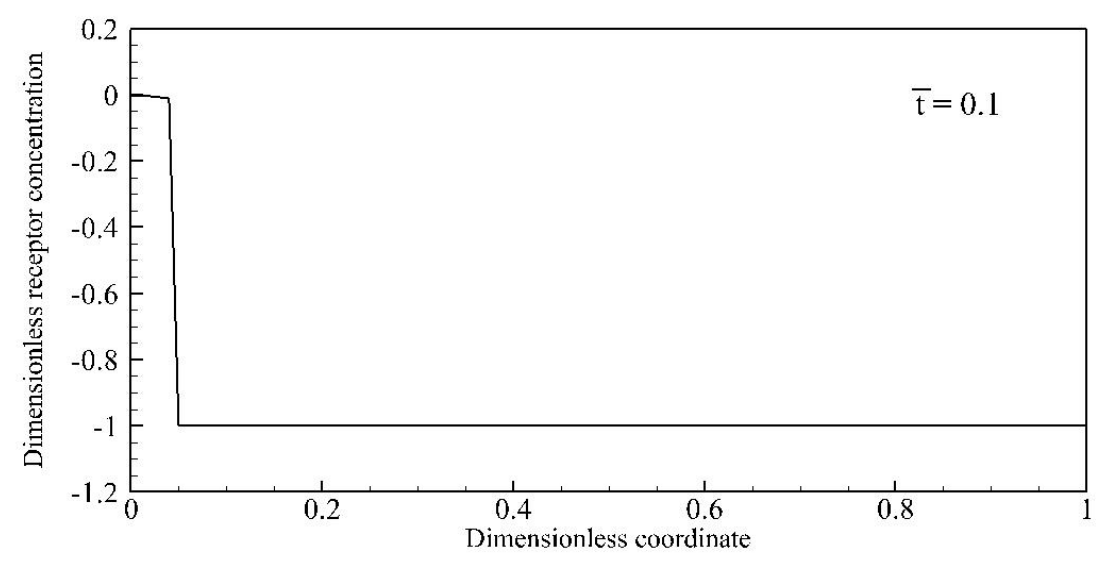

(a)

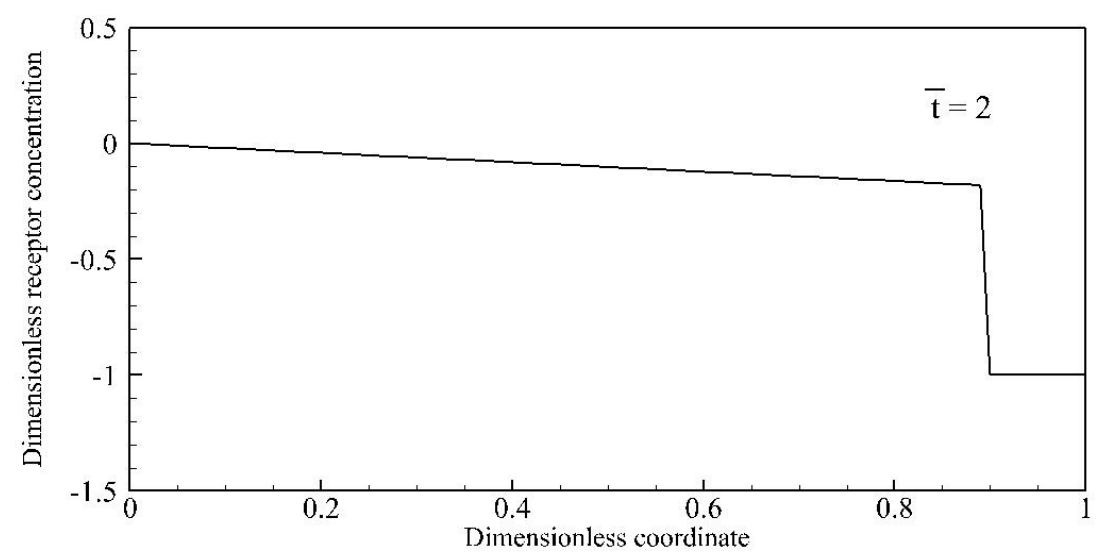

(b)

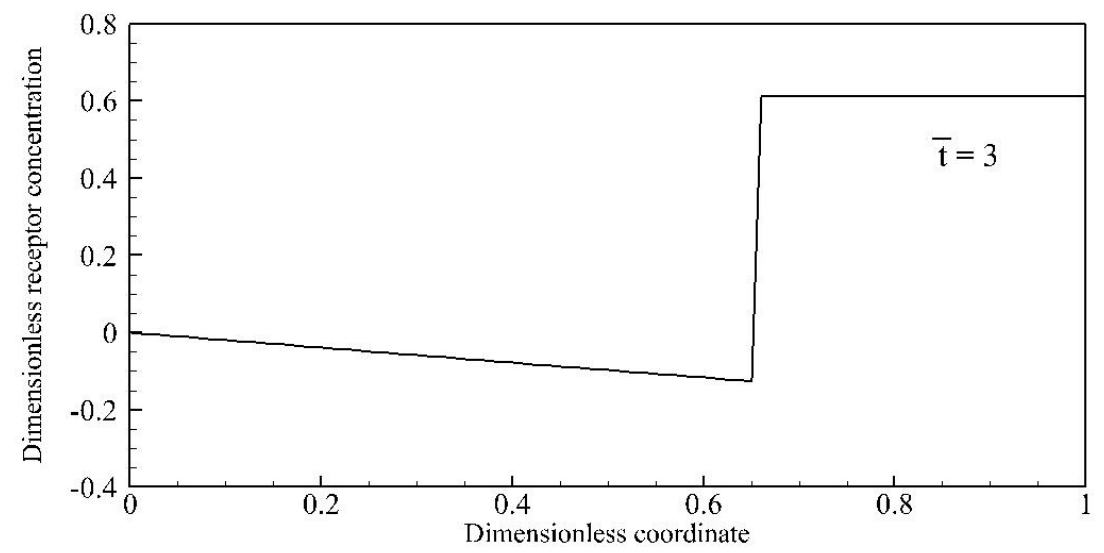

(c)

Fig.3 Change of dimensionless concentration for receptor after the contact edge with dimensionless coordinate for dimensionless relaxation time of $\beta=5$; a) $\bar{t}=0.1$; b) $\bar{t}=2$; c) $\bar{t}=3$ 
bioRxiv preprint doi: https://doi org/10.1101/808212 this version posted October 17,2019 . The copyright holder for this preprint (which was not certified by peer review) is the author/funder, who has granted bioRxiv a license to display the preprint in perpetuity. It is made available under aCC-BY 4.0 International license. 
bioRxiv preprint doi: https://doi.org/10.1101/808212; this version posted October 17,2019 . The copyright holder for this preprint (which was not certified by peer review) is the author/funder, who has granted bioRxiv a license to display the preprint in perpetuity. It is made available under aCC-BY 4.0 International license.

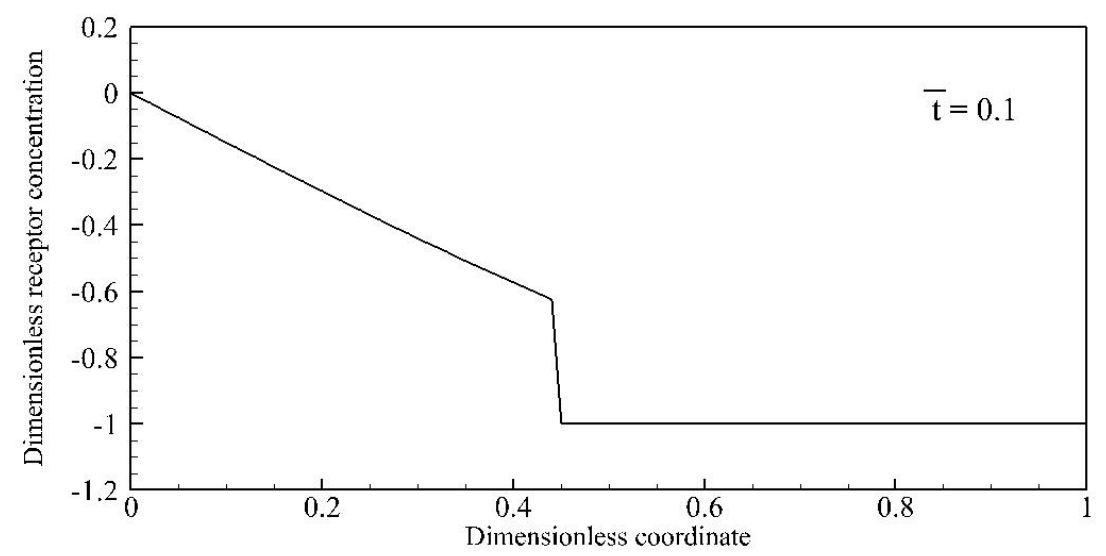

(a)

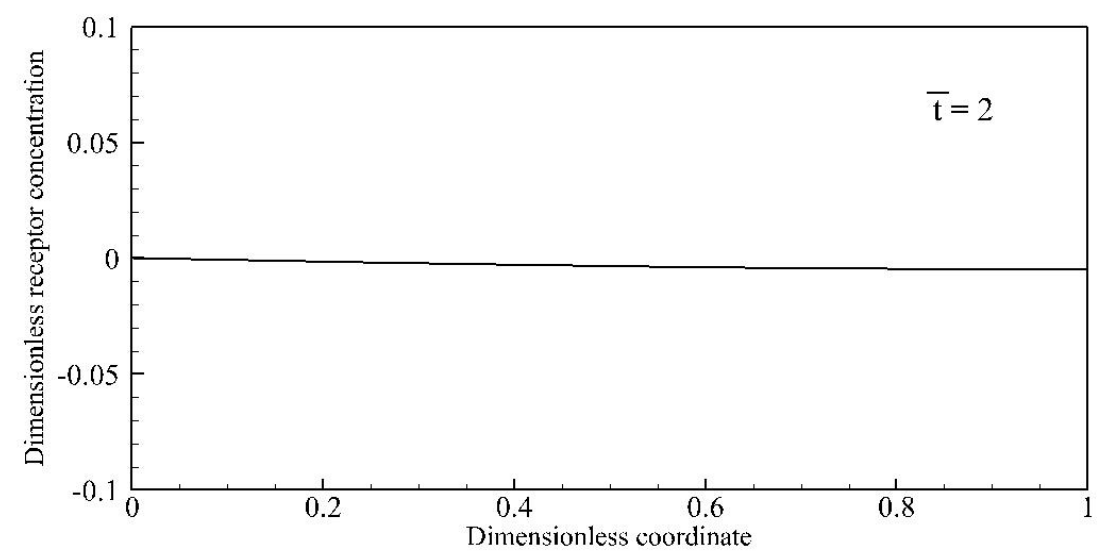

(b)

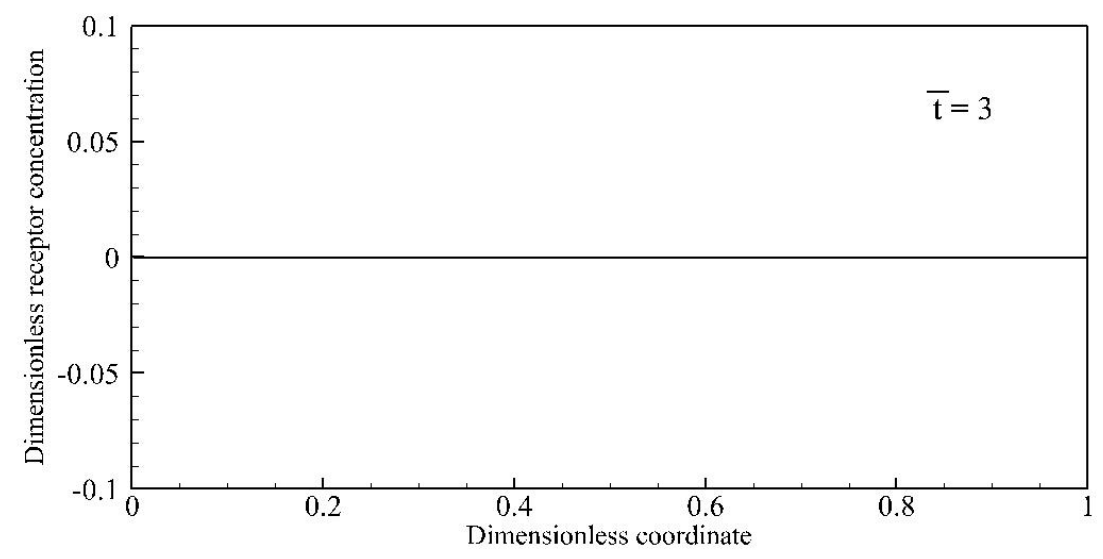

(c)

Fig.4Change of dimensionless concentration for receptor after the contact edge with dimensionless coordinate for dimensionless relaxation time of $\beta=0.05$; a) $\bar{t}=0.1$; b) $\bar{t}=2$; c) $\bar{t}=3$ 
In Fig. 5a, the change of contact length a(t) with penetration time is shown for assumed $\beta=5$ .According to this figure the value of $\mathrm{a}(\mathrm{t}) / \mathrm{L}$ in this condition cannot exceed 0.34 . The penetration time of a molecule is when the a(t) becomes equal to $\pi D / 2$. So, the molecules with $\mathrm{D} / \mathrm{L}$ larger than 0.22 cannot penetrate to the host cell and experience an oscillatory motion. On the other hand, the smaller molecules will penetrate during certain dimensionless time of 0 to 4.5 as shown in this figure. For example, the penetration time of a molecule with a diameter of 1 micron into a host cell with a length of 10 micron, corresponds to $\bar{t}=2.2$ when the a(t)/L reaches 0.16 . The results reveal there is an upper limit for the size of biomolecules penetration into host cell, while this phenomena has not seen already. The porpuse of this article is not to obtain an optimum size for biomolecule penetration into host cell. These results show that molecules with radius smaller than the critical size, $D_{c r}$, can penetrate into host cell. It should be noted that in this study $\beta$ is an assumed value and is not according to exact properties of the cell membrane. In order to find the exact value of $\beta$ one should use some extensive molecular dynamics simulations or experimental observations. So, the exact value of this critical size can be obtained considering an exact value for the relaxation time of cell membrane.

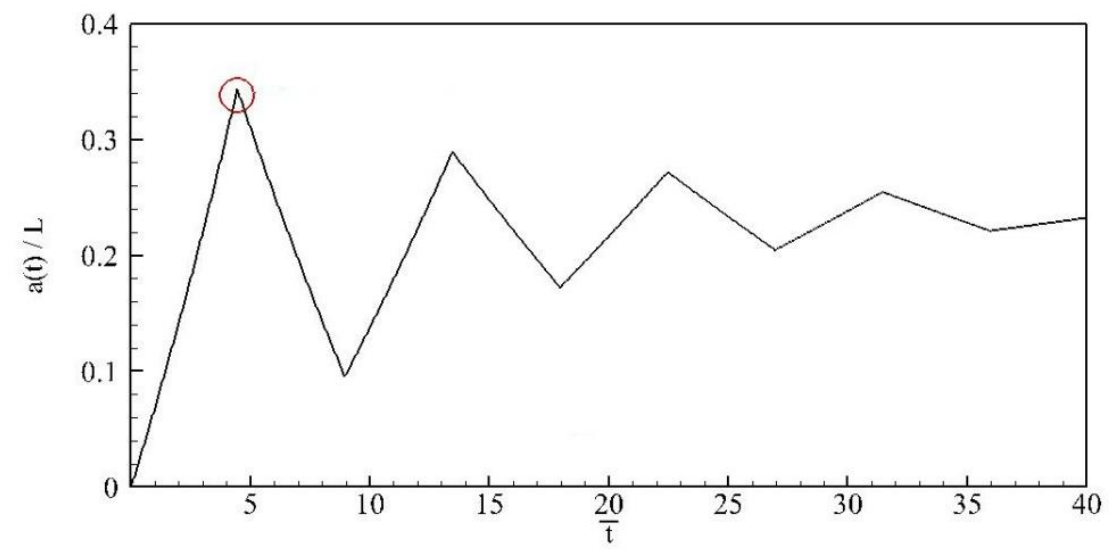

(a)

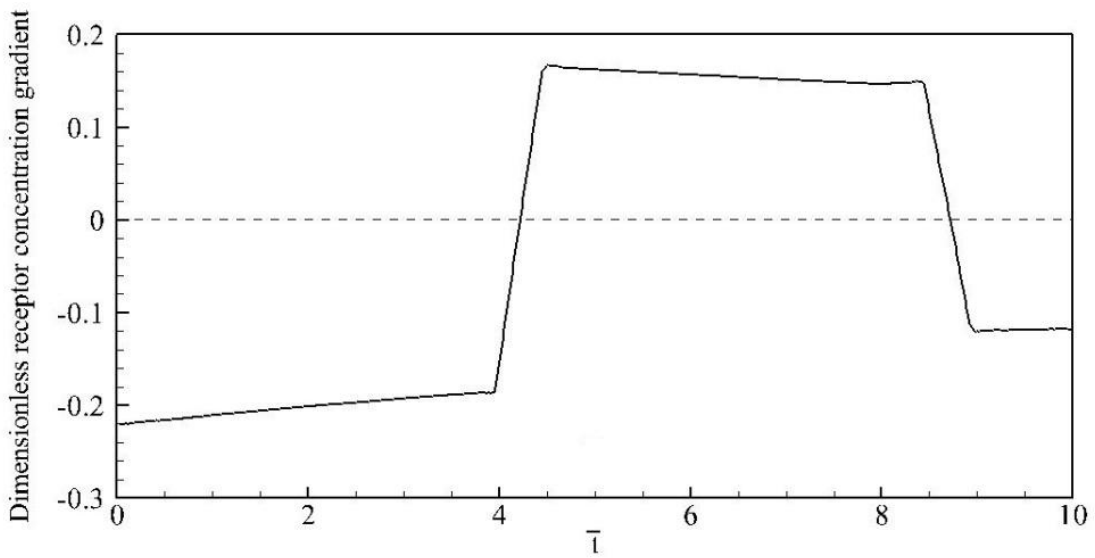

(b) 
Fig.5(a) change of contact length a(t) with time; (b) change of gradient of receptor concentration directly in front of the contact length; $\beta=5$

It can be deduced that molecules by the surface area larger than $\mathrm{A}_{\mathrm{cr}}$ will experience an oscillatory motion for entering the cell and finally they could not penetrate the cell. The change of gradient of the receptor concentration directly in front of the contact length is shown in Fig. 5b. Our model predicts that mass flux will oscillatory give positive and negative values and prohibit the larger target molecules from entering the cell via endocytosis. This result is an important finding in drug delivery mechanisms.

\section{Conclusion}

In this paper receptor mediated endocytosis process is investigated assuming that the diffusion model of the receptor molecules in the lipid bilayer is non-Fickian. Different relaxation lag time is chosen to investigate the effect of lag time on the speed of mass transport. Our results show that in smaller relaxation times, the receptor diffusion behavior obtained from lag model is close to Fick's model. In larger relaxation times, the molecules which their surface are larger than - $\mathrm{A}_{\mathrm{cr}}{ }^{-}$ will oscillate in the cell membrane and could not penetrate the cell. The main objective of our study is to provide an analytical basis helping prediction of the size effect of receptor mediated endocytosis. This prediction may provide some advices for drug delivery systems. The size of the drugs is an important factor in targeting drug delivery for increased efficiency and selectivity.

\section{References:}

[1] Amodeo GF, Scorciapino MA, Messina A, De Pinto V, Ceccarelli M. Charged residues distribution modulates selectivity of the open state of human isoforms of the voltage dependent anion-selective channel. PLoS One 2014;9:e103879.

[2] Roux B, Li H, Chowdhary J, Harder E, Lopes PEM, Huang L, et al. Ion Channel Simulation with Explicit Solvent and Lipid Membrane Based on the Drude Polarizable Force Field. Biophys J 2014;106:44a.

[3] Ghaffari H, Grant SC, Petzold LR, Harrington MG. Regulation of cerebrospinal fluid and brain tissue sodium levels by choroid plexus and brain capillary endothelial cell $\mathrm{Na}+\mathrm{K}+$-ATPases during migraine. bioRxiv. 2019 Jan 1:572727. https://doi.org/10.1101/572727

[4] Ball P. The Importance of Water. Astrochem. Astrobiol., Springer; 2013, p. 169-210. 
[5] Papadopoulos MC, Verkman AS. Aquaporin water channels in the nervous system. Nat Rev Neurosci 2013;14:265-77.

[6] Damirchi, B., Rismanian, M., Saidi, M. S., \& Firoozabadi, B. "Coarse grain molecular dynamics simulation of drug carrier penetration into cell membrane." (2015): 316-322..

[7] Damirchi, B., Saidi, M. S., Rismanian, M., Firoozabadi, B., \& Amininasab, M. (2016). An alternative mechanism for the formation of high density lipoprotein in peripheral tissue. Scientia Iranica. Transaction B, Mechanical Engineering, 23(2), 600.

[8] Damirchi, B., Rouhollahi, A., Sohrabi, S., \& Mehr, S. M. N. (2013, November). Modeling and Stability Analysis of Truncated High Density Lipoprotein (HDL) System Using Martini Coarse Grain Technique. In ASME 2013 International Mechanical Engineering Congress and Exposition (pp. V03AT03A069-V03AT03A069). American Society of Mechanical Engineers.

[9] Shamloo, A., Nikbin, E., Mehboudi, N., \& Damirchi, B. (2014, August). Homo-oligomerization of transmembrane $\alpha$-domain of integrin. In 2014 36th Annual International Conference of the IEEE Engineering in Medicine and Biology Society (pp. 1162-1165). IEEE.

[10] Di Fiore PP, von Zastrow M. Endocytosis, signaling, and beyond. Cold Spring Harb Perspect Biol 2014;6:a016865.

[11] Echavarria-Heras H, Solana-Arellano E, Leal-Ramirez C. Surface aggregation patterns of LDL receptors near coated pits II. The retrograde membrane flow-diffusion and generalized plaqueform insertion mechanism. Math Med Biol 2012;29:109-30. doi:10.1093/imammb/dqq018.

[12] Prabha S, Zhou WZ, Panyam J, Labhasetwar V. Size-dependency of nanoparticle-mediated gene transfection: studies with fractionated Nanoparticles. Int J Pharm 2002;244:105-15.

[13] Aoyama Y, Kanamori T, Nakai T, Sasaki T, Horiuchi S, Sando S, et al. Artifical viruses and their application to gene delivery. Sizecontrolled Nanoparticles., gene coating with glycocluster. J Am Chem Soc 2003;125:3455-7.

[14] Nakai T, Kanamori T, Sando S, Aoyama Y. Remarkably size-regulated cell invasion by artificial viruses. Saccharide-dependent self-aggregation of glycoviruses and its consequences in glycoviral gene delivery. J Am Chem Soc 2003;125:8465-75.

[15] Osaki F, Kanamori T, Sando S, Sera T, Aoyama Y. A quantum dot conjugated sugar ball and its cellular uptake on the size effects of endocytosis in the subviral region. J Am Chem Soc 2004;126:6520-1.

[16] Bao, G., Bao, X.R. Shedding light on the dynamics of endocytosis and viral budding. Proc Natl Acad Sci USA 2005;102:9997-8.

[17] Decuzzi, P., Ferrari M. The receptor-mediated endocytosis of non-spherical particles. Biophys J 2008;94:3790-7.

[18] Zhang S, Li J, Lykotrafitis G, Bao G, Suresh S. Size-dependent endocytosis of nanoparticles. Adv Mater 2009;21:419-24. 
[19] Jin H, Daniel A, Heller AD, Sharma R, Strano MS. Size-dependent cellular uptake and expulsion of single-walled carbon nanotubes: single particle tracking and a generic uptake model for nanoparticles. ACS Nano 2009;3:149-58.

[20] Gao H, Shi W, Freund LB. Mechanics of receptor-mediated endocytosis. Proc Natl Acad Sci U S A 2005;102:9469-74.

[21] Shi W, Gao H, Freund LB. Modeling receptor-mediated endocytosis via mechanics of cell adhesion. In: Ozkan, C.S., Rosei, F., Lopinski, G.P., Wang, Z. L. (Eds.). Mater Res Soc Symp Proc 2006;901E Warre:0901-Ra02 - 01-Rb02 - 01.

[22] Rismanian M, Saidi MS, Firoozabadi B. Na+ Permeation through its Protein Channels; From Molecular Dynamics to Continuum Modeling. Sci Iran 2014.

[23] Freund LB, Lin Y. The role of binder mobility in spontaneous adhesive contact and implications for cell adhesion. J Mech Phys Solids 2004;52:2455-72.

[24] Dill KA, Bromberg S. Molecular driving forces: statistical thermodynamics in chemistry and biology. Garland Science; 2003.

[25] Helfrich W. Elastic properties of lipid bilayers: theory and possible experiments. Z Naturforsch C 1973;28:693.

[26] Van Effenterre D, Roux D. Adhesion of colloids on a cell surface in competition for mobile receptors. EPL (Europhysics Lett 2003;64:543.

[27] Tzlil S, Deserno M, Gelbart WM, Ben-Shaul A. A statistical-thermodynamic model of viral budding. Biophys J 2004;86:2037-48.

[28] Briggs JAG, Wilk T, Fuller SD. Do lipid rafts mediate virus assembly and pseudotyping? J Gen Virol 2003;84:757-68.

[29] Griffiths G, Warren G, Quinn P, Mathieu-Costello O, Hoppeler H. Density of newly synthesized plasma membrane proteins in intracellular membranes. I. Stereological studies. J Cell Biol 1984;98:2133-41. 